\title{
El Centro de Innovación de la UCA
}

C on el objetivo de potenciar las iniciativas que se realizan en la Universidad Centroamericana desde distintas instancias para incentivar la innovación en sus estudiantes, la UCA contará con un novedoso Centro de Innovación. Es éste un centro con un enfoque interdisciplinario desde su nacimiento, pues es el resultado de una estrecha colaboración entre la Facultad de Humanidades y Comunicación, la Facultad de Ciencias Económicas y Empresariales, la Facultad de Ciencia, Tecnología y Ambiente, y la Dirección de Investigación de Vicerrectoría Académica. El centro tendrá un énfasis de servicio a empresas, medios de comunicación independientes y organizaciones de la sociedad civil. Así mismo, en consonancia con la misión de la UCA, procurará convertirse en un punto de referencia de la innovación social en el país. Por medio del Centro de Innovación, la universidad acercará a estudiantes de pregrado a problemas reales del entorno para que, contando con acompañamiento y asesoría cercana, los analicen y busquen soluciones viables que partan de sus conocimientos profesionales, sus competencias investigativas, y su capacidad de diálogo interdisciplinario.

El tema de la innovación - y su asociación con el emprendedurismo actualmente forma parte de narrativas predominantes en círculos académicos y sectores del Estado. Se habla de innovación y emprendedurismo desde distintas ópticas, que coinciden siempre en confirmar su importancia apremiante: así, se habla de éstos como una vía para dinamizar la macroeconomía del país, como una inversión positiva que tanto los individuos como las organizaciones deberían hacer, o como la única alternativa para muchas personas miembros de la PEA en un país de alto desempleo. Aparentemente no queda nada que decir para convencer a los líderes de organizaciones públicas y privadas de asumir el credo de la innovación y el emprendedurismo. El tema ha sido expuesto y conversado en el país desde, por lo menos, 1995, año en que se creó el Consejo Nicaragüense de Ciencia y Tecnología (CONICYT) mediante Decreto No. 5-95. Además, desde el año 2008 el país cuenta con un Anteproyecto de Ley General de Ciencia, Tecnología e Innovación. A nivel de las universidades del CNU, la bina de innovación y emprendedurismo ha estado presente fuertemente por lo menos desde los últimos diez años. Entre muchas iniciativas sobresalen, en el caso de la UCA, el Programa Universidad Emprendedora (2007-2010) y el Proyecto CESAR (2011-2013). Por lo tanto, la creación del Centro de Innovación en la UCA no se trata de una decisión tomada a la ligera, sino del paso lógico que se da tras un considerable proceso de preparación.

El Centro de Innovación de la UCA podrá existir gracias al conocimiento acumulado que tiene la universidad en la promoción de la innovación y el emprendedurismo desde distintas facultades e instancias, como la Oficina de Relaciones con el Entorno Socioeconómico (ORES) de la Dirección de Investigación. Pero también será posible gracias a la subdonación facilitada por USAID y la Fundación Violeta Barrios de Chamorro. Con el impulso de este proyecto, a partir de agosto de 2016 y en el lapso de ocho meses, habremos instalado un Centro de Innovación de punta en la Universidad Centroamericana, equipado siguiendo lineamientos y asesoría de expertos internacionales de universidades hermanas de Latinoamérica, pero muy ajustado a la realidad nicaragüense. El centro llenará un vacío señalado en repetidas ocasiones por expertos en la materia y allegados a la educación superior, pero también procurará dar un toque propio a la innovación, procurando que el trabajo que en él se realice apunte siempre al enfoque de la UCA, de contribuir a la "construcción de una sociedad justa, crítica, inclusiva y comprometida con el bien común”.

\section{Wendy Bellanger}

Editora

\section{3}

\section{Editorial}

